\title{
Comparisons of Body Image Perceptions of a Sample of Black and White Women with Rheumatoid Arthritis and Fibromyalgia in the US
}

\author{
Josephine E.A. Boyington ${ }^{*}, 1$, Britta Schoster ${ }^{2}$ and Leigh F. Callahan ${ }^{2,3,4,5}$ \\ ${ }^{I}$ National Institutes of Health, National Heart Lung and Blood Institute, Bethesda, MD, USA \\ ${ }^{2}$ Thurston Arthritis Research Center, University of North Carolina at Chapel Hill, Chapel Hill, NC, USA \\ ${ }^{3}$ Division of Rheumatology, ${ }^{4}$ Department of Medicine, ${ }^{5}$ Department of Social Medicine, UNC, Chapel Hill, NC, USA
}

\begin{abstract}
Objective: To explore the disease-related, body image (BI) perceptions of women diagnosed with, rheumatoid arthritis (RA) and fibromyalgia (FM).

Methods: A purposive sample of twenty-seven females participated in individual semi-structured phone interviews to elicit BI perceptions relative to pain, activity limitations and coping measures. Sessions were digitally recorded, transcribed verbatim, and content analyzed.

Results: Body image perceptions relative to 5 major themes emerged in the analysis. They focused on Pain, Disease Impact on Physical and Mental Function, Weight, Diseased-Induced Fears and, Coping measures. Pain was a common experience of all participants. Other troubling factors verbalized by participants included dislike and shame of visibly affected body parts, and disease-induced social, psychological and physical limitations. RA participants thought that manifested joint changes, such as swelling and redness, undergirded their prompt diagnosis and receipt of health care. Contrarily, women with fibromyalgia perceived that the lack of visible, disease-related, physical signs led to a discounting of their disease, which led to delayed health care and subsequent frustrations and anger. All but one participant used prayer and meditation as a coping measure.

Conclusion: The body image perceptions evidenced by the majority of participants were generally negative and included specific focus on their disease-affected body parts (e.g. joints), mental function, self-identity, health care experiences, activity limitations and overall quality of life. Given the global effect of RA and FM, assessment and integration of findings about the BI perceptions of individuals with FM and RA may help define suitable interdisciplinary strategies for managing these conditions and improving participants' quality of life.
\end{abstract}

Keywords: Black women, body image, fibromyalgia, perceptions, rheumatoid arthritis, white women.

\section{INTRODUCTION}

Body image (BI), the subjective perception of the body, is differentially defined as "that part of the self-image which pertains to the physical body," or a person's perceptions, feelings and thoughts about his or her body [1-3]. Conceptually, BI consists of two components: the perceptual and the affective, and is generally described as negative or positive. The perceptual component refers to the assessment of the body's appearance, size, shape and function, and the affective component, refers to the attitudes, cognitions, feelings and behaviors toward the body, its processes and functions [2-5]. For example when an individual states that his/her body is 'fat', the perceptual component is evidenced, and contrastingly when he/she further states a dislike for that 'fat' body, the affective component is evidenced $[2,6]$. Assessments of BI in the literature include both separate and

*Address correspondence to this author at the Division of Cardiovascular Sciences/Clinical Applications and Prevention Branch, National Heart Lung and Blood Institute 6701 Rockledge Drive, Suite 10024, Rockledge II, Bethesda, MD 20892, USA; Tel: 301-435-0446;

E-mail: boyingtonje@mail.nih.gov combined evaluations of the two components and have been synonymously termed "body concept," "body scheme," "body satisfaction", "body identity" and "body experience" among others [4]. In this study we use the term 'body image' to represent participants' combined evaluations of the affective and perceptive components.

In the medical and psychological literatures, chronic pain, profound physical changes, and their resultant feelings reportedly influence individuals' perceptions of self-identity, self-esteem, and mood, and consequently affect their response to disease, and their likelihood to engage in selfcare measures [2-13]. Grogan and colleagues note that "unwanted physical changes to our bodies due to illness, ... can affect body image, resulting in poor self-esteem and reduced quality of life" [1].

Rheumatic diseases which include over 100 chronically painful conditions affect over 50 million Americans and can cause organ and joint destruction as well as severe pain, disability and eventual mortality $[14,15]$. Chronic pain and disease-related disability, two variables associated with inflammatory rheumatic diseases, are also associated with reduced quality of life $[16,17]$ and BI disturbances. 
Monaghan and colleagues report that knowledge about BI perceptions of individuals with rheumatic conditions is sparse, and Lotze and Mosley note that specific knowledge about BI perceptions and pain is little known outside of conditions resulting in amputations, or in complex regional pain syndrome (CRPS) studies [3, 18]. CRPS is a condition that generally affects pain perception in major regions of the body such as a limb or the spine. Taleporos and Mccabe further note that investigations of the impact of physical disability on BI have been largely neglected [19]. Current literature indicates that the majority of inflammatory diseasefocused BI studies have mainly targeted conditions with visible deformities, (rheumatoid arthritis, systemic lupus, erythematosus and ankylosing spondylitis) $[12,13,18,20]$, and have generally reported on Caucasian participants [13, $18,20]$. As a result Monaghan et al. have specifically called for further investigation in other types of populations affected by rheumatic conditions [18]. The goal of this study was to understand the body image perceptions and experiences of black and white females with doctordiagnosed, Rheumatoid Arthritis (RA) and/or Fibromyalgia (FM), two of the more common, painful and debilitating rheumatic conditions that affect women.

\section{METHODS AND MEASUREMENT}

\section{Recruitment}

Since this study was about understanding the body image perceptions of women with two types of rheumatic conditions, the only inclusion criteria was that participants self-identify as either a black or white female, with doctordiagnosed RA or FM or both. We drew our participant samples from the Musculoskeletal Disease (MSK) research database and from a local rheumatology clinic (the Daughtridge Arthritis Clinic, North Carolina). The MSK is a University of North Carolina (UNC) research database with contact information for 2075 individuals with doctordiagnosed musculoskeletal diseases, who previously consented to, participate in future community-based research studies. In 2007, only 60 of candidates in the database were black females with doctor-diagnosed RA or FM. In fact, at the time of this study, the database had stopped recruiting participants and participants' contact information were not being updated. Given this limitation we therefore selected all 60 of the black females with RA or FM, and added an additional 60 white females (selected in alphabetical order by surname) with RA or FM, to form our target recruitment pool. To this pool of 120 individuals, we mailed recruitment letters describing the study's purpose and duration, participants' expected commitment and a toll free contact number for the study. We followed up two weeks later with a phone call during which we ascertained participants' receipt of the letter, clarified questions about the study and determined their willingness to participate. For interested individuals, we telephone-consented them during the initial phone call and scheduled them for a later phone-interview. We were only able to reach thirteen whites and two (2) of the 60 blacks drawn from the MSK database. We therefore added a local rheumatology clinic with a high population of black patients as a recruitment site. From there we recruited 12 additional black patients, giving us a total sample of 13 white and 14 black females. The study was approved by the UNC institutional review board.

\section{Interview}

We used a study-developed semi-structured, in-depth interview guide to conduct twenty-seven separate, 45 to 90 minute, disease-focused, phone interviews. Questions in the interview guides were based on findings in the literature about body image perceptions and painful chronic conditions. We collected demographic and medication data via a self-reported survey that preceded the interview, and then used the interview questions, with appropriate probes, to examine participants' BI experiences in three areas of interest, namely: disease-related pain, activity limitations, and coping measures. A hired transcriptionist and the first author both transcribed the audiotaped sessions verbatim into textual documents.

\section{Analysis}

Our analysis of the textual interview data involved first reading through the transcripts in their entirety to gain a general understanding of participants' experiences. We then re-read the texts and coded them using codes previously generated from the interview guide and subsequently generated from themes arising from participants' responses. Mirroring the color coding approach in ATLAS.ti 6 qualitative data analysis software [21] we assigned separate colors to each code to create a visual map. All textual documents were coded by the first and second authors. To ensure reliability and validity of the coding scheme, the initial coding was independently done, then the coded texts were reviewed together and discrepancies resolved through face to face discussions. After developing consensus on the coding results, we then used the color-generated maps to examine participants BI perceptions within and across conditions (FM or RA) and across emergent themes.

\section{RESULTS}

\section{Demographics}

This sample of 27 females (13 whites and 14 blacks) ranged in age from 42-77 years. Almost two-thirds were married and college educated (65.4\%). Slightly more than a third $(38.5 \%)$ were employed full-time (Table 1). There were in total $10 \mathrm{RA}, 11 \mathrm{FM}$ and 6 FM-RA participants and those with RA were slightly older than those with FM and FM-RA (Table 2). In the findings below women $\leq 60$ years are referred to as younger women, and those above 60 years old older women. All participants reported concomitant, inflammatory diagnoses such as either, osteoarthritis, sarcoidosis, inflammatory bowel syndrome, neck, back or spine conditions. Six women, four of whom were black, reported FM as a comorbid condition that existed with RA. The mean disease duration for all participants was $12.4 \pm 10.2$ years. Except for one individual, all participants also reported at least one of the following non-rheumatic, comorbid condition: depression, diabetes, hypertension, leaky bladder, fluctuating potassium levels, esophageal spasm and allergies. Disease-specific demographics are detailed in Table 2. 
Table 1. Overall and race-specific demographics.

\begin{tabular}{|c|c|c|c|}
\hline & $\begin{array}{c}\text { Overall } \\
\text { Sample }\end{array}$ & $\begin{array}{c}\text { Black } \\
\text { Participants }\end{array}$ & $\begin{array}{c}\text { White } \\
\text { Participants }\end{array}$ \\
\hline \hline Sample Size & $27(100 \%)$ & $14(51.9 \%)$ & $13(48.1 \%)$ \\
\hline Age & $55.9 \pm 9.1$ & $54.5 \pm 10.9$ & $57.5 \pm 6.9$ \\
\hline Employed & $10(37 \%)$ & $11(78.6 \%)$ & $6(46.2 \%)$ \\
\hline Married & $17(63.0 \%)$ & $8(57.1 \%)$ & $9(69.2 \%)$ \\
\hline BMI & $34.3 \pm 6.9$, & $36.4 \pm 6.2$ & $31.8 \pm 7.0$ \\
\hline
\end{tabular}

Table 2. Demographics by disease group.

\begin{tabular}{|c|c|c|c|}
\hline & $\begin{array}{c}\text { RA } \\
\text { Participants }\end{array}$ & $\begin{array}{c}\text { FM } \\
\text { Participants }\end{array}$ & $\begin{array}{c}\text { FM-RA } \\
\text { Participants }\end{array}$ \\
\hline \hline Sample Size & 10 & 11 & 6 \\
\hline Race: Black & $5(50 \%)$ & $5(45.5 \%)$ & $4(66.7 \%)$ \\
\hline Race: White & $5(50 \%)$ & $6(54.5 \%)$ & $2(33.3 \%)$ \\
\hline Age & $58.8 \pm 9.1$ & $55.3 \pm 8.6$ & $52.3 \pm 9.8$ \\
\hline Employed & $5(50 \%)$ & $7(63.7 \%)$ & $5(83.3 \%)$ \\
\hline Disease Duration & $11.7 \pm 11.0$ & $16.4 \pm 10.2$ & $6.0 \pm 5.1$ \\
\hline Marital Status & $6(60.0 \%)$ & $7(72.7 \%)$ & $3(50.0 \%)$ \\
\hline BMI & $33.3 \pm 6.4$ & $33.6 \pm 6.5$ & $38.1 \pm 8.7$ \\
\hline
\end{tabular}

Interview Findings: Perceptions About Body Shape, Pain, Appearance and Coping

\section{Pain}

For both FM and RA participants, pain was the initial and primary symptom of disease onset. It was described as acute, localized, and immediately debilitating for people with RA, and gradual, generalized and progressively debilitating for people with FM. Younger participants with RA reported a rapid onset of pain, that was physically debilitating. Older black participants with RA reported that arthritis pain and related limitations were an expected part of aging, and were the least bothered by their pain symptoms. For RA participants, the joint swelling and joint stiffness which accompanied their pain onset was seen as the primary reason for seeking and receiving care. Contrastingly, participants with FM and those dual-diagnosed with FM-RA reported that they too pursued care because of progressive and debilitating pain, however, the lack of visible, physical signs of disease led to a discounting of their reported experience. As such they reported feelings of frustration, anger and helplessness due to their delayed medical care. Sample verbatim perceptions are listed in Table $\mathbf{3}$.

\section{Disease Impact on Physical and Mental Functions}

Compared to RAs, FM participants reported more profound impact of fibromyalgia symptoms on their physical, emotional, mental functions and social roles. Individuals with RA surmised that with treatment, their pain was manageable. However, they also thought that swelling and joint stiffness, would continue to affect their future function and appearance. Using descriptors such as 'crooked joints', 'bent back', 'smallish looking legs' and 'large body' (prednisone side-effect) they described their personal perceptions of their affected bodies and noted that decreased body strength, decreased joint flexibility and visible changes in the look and shape of their bodies made them feel embarrassed in public.

Table 3. Exemplar perceptions - related to pain and the health care experience.

".... the first day I went to him, he saw the state I was in ... he check all my fingers, and my feet, and my knee was swollen up so much and everything, and all he said was you have rheumatoid arthritis and he had known what I had right there." (Black RA)

"..I had a devil of a time convincing people that you know something was physically wrong with me. And because they gave me all kinds of $x$-rays and tests and they never could find anything with this pain thing...” (Black FM)

"I mean you know just like I told you it's hard to get your family to understand, your employers...you go to work everyday even though you're in pain. Nobody knows you're in pain.” (White-FM)

“...it took them a year to diagnose what was wrong with me because they said I had sero-negative rheumatoid arthritis because all my lab tests were normal. All my x-rays were normal.... And for a year, they treated me as if I was drug seeking. And wouldn't give me anything... And I finally I told him \{my doctor\} I said I'm sorry I'm not deformed for you. I'm sorry the lab tests are not abnormal for you.." (White FM)

"I just don't know where to go and I'm really, like the rheumatologist, he didn't give me a whole bunch to go on.... I don't think that a lot's being done to help me get better but just to make the pain go away."(Black-FM)

"Society thinks that it's all in your mind...Honey, I've been trying to get disability for 10 years now, and nothing. I have had appeals, I've been before a judge and the first thing he asked me had I had surgery and he denied me...And it blew my mind...I mean you know how hurtful is that?" (Black-FM)

Contrastingly, FMs listed an assortment of additional symptoms including numbness of extremities, intense fatigue, irritable bowel syndrome, overactive bladder, restless leg syndrome, dry mouth, frequent forgetfulness, sleep alterations, and inability to concentrate, as very troubling. Among these, forgetfulness and the inability to concentrate were noted as most frightening, and was labeled "fibro fog." It was perceived to be related to both the disease and a side-effect of medications and deemed, by FMs, as the primary cause of their inability to carry out activities of daily living. See Table 4 for representative disease impact statements.

\section{Weight Gain}

Both groups of participants reported excess weight gain, perceived it as negative and related it to their disease experiences. Individuals with RA stated that fatigue and stiffness, and to a lesser extent pain, prevented physical activity and thereby led to weight gain. Contrastingly, FMs perceived that uncontrolled pain, fatigue, and their prescribed medications led to their weight gain. In describing their bodies, RAs focused on the attractiveness of specific body parts, whereas FMs focused on the function of the whole body. A sampling of participants' appearance and weight related perceptions are listed in Table $\mathbf{5}$. 
Table 4. Exemplar perceptions related to Disease impact on physical and mental functions.

"It's just like you're in a shell or something and you can't get out of it.
It's just bad honey. I pray you never get it."(Still Crying - Black-FM-
RA)
“An old woman, in pain... Well I am 46, I will be next month and I
feel 106.” (Black FM-RA)
“Emotionally....it was just frustrating that my joints didn't work as
well. Ah it made it difficult for me to exercise... so it's just been
frustrating. I think, I was, when my hands were so swollen...very self-
conscious about my left hand. And when, my friends would notice, I
would sort of hide it.” (White-RA)
“.. it's like being an infant in some of the regards of what you're
capable of doing and not doing.” (White-FM)
"I think well... definitely my hands were prettier. My knuckles weren't
so fat and I didn't have like the bunion type things on my feet and
could wear, you know pretty dainty little shoes like sandals, and heels,
and things. And I don't wear those anymore because they're
uncomfortable." (White RA)
“With RA since it's in my hands, it's visible and I don't like it when
I'm in a flare-up and people say, oh my god, look at your hands, you
know.. I'm not crippled though to the point like I say, you've seen
people with their hands in a curling fashion you know.” (White-RA)

Table 5. Exemplars of perceptions related to weight.

\begin{abstract}
"I feel like [the disease] that's part of the reason I've gained weight. I was much slimmer because I was so active. I used to go out dancing and it's just hard to do those kinds of things anymore because not so much the pain anymore because the medication alleviates that, but I just don't have the kind of stamina that I used to have, and I think that is definitely the rheumatoid arthritis...I've put on probably 35 pounds since I got the rheumatoid arthritis." (White $R A$ )
\end{abstract}

"I used to do some modeling. I was very, very fit, very good posture, and it's okay now. But it's not as it used to be in terms of weight. It's just so much more than I wish it was.” (Black-FM-RA).

"I think you know that I could look so much better, if I would lose weight. Posture, my posture could be better but I never think about my posture. ...But my body as far as it goes I feel like I could look so much better, as a result I think I would look younger and that that's how I feel about it...It's just in my own head where I feel like I would like to be considered more normal. I don't want to know that I have a problem or disease or...well, that's sounds severe doesn't it. I wouldn't say I'm not normal simply because I'm not crippled but I wouldn't say not normal I would say it makes me feel like I have a flaw. That works probably better to describe it." (White RA)

\section{Disease-Induced Fears}

With the multiple symptoms experienced by FMs, they often felt like they were not in control of their bodies and were fearful about this. Overt fears they verbalized included the 'fear of traveling' -because of uncertainties about bowel and bladder control-, 'the fear of getting stuck' in compromised situations (i.e. in public lavatories) because of joint stiffness, numbness and pain, and most alarming for them, the 'fear of being invalid' at a young age and becoming totally dependent on others for their care. FMs perceived their whole bodies as deteriorating, and used terms such as 'old' and 'infantile' to describe their bodies. To inject a measure of control into their lives, they reported using many types of alternative health options such as massage, meditation, chiropractors, feldenkrais, etc. to manage their symptoms. In contrast, participants with RA mostly feared falling, being crippled in the future, and developing resistance to their medications. To reduce the possibility of drug resistance, both black and white RAs reported that they only took their medications when they thought it was absolutely needed, so that their bodies did not get too used to the medicines. See exemplar comments in Table 6.

Table 6. Exemplars of perceptions related to disease induced fears.

"It's everything you've got to do... I can't get up off of some toilets
(NUMBNESS)... is there a bathroom close enough I can get to
(IRRITABLE BOWEL)? Am I going to have to stand for any length of
time (FATIGUE)? Am I going to have to sit in a really hard chair for
any period of time (PAIN AND NUMBNESS)? I mean it's everything.
Things that other people don't even think about... It's everything
you've got to do. I can't open a jar. I can't open a bottle of pop. I can't
get up off some toilets. I've been stuck when we were traveling where I
had to wait until my husband just said what's taking her so long? And
I screamed for him to come in and help me up. You're very conscious
of going up or down stair...because you can fall...” (White-FM)

"And there's times when I just can't even wrap my brains around anything... I can't follow the train of concentration you know what I'm trying to say?.. And they kept giving me more and more pain medicine. It was so my brain function was not there. I couldn't concentrate to do things. I couldn't even concentrate to sit and read a journal...So it was getting to be fewer and fewer things that I got pleasure out of." (White FM-RA)

"Yes I mean I have a lot of fears, I just have a lot of fears that you know I'm going to have to be in an assisted living or like that. That's the way I feel because now I'm only 41 and I have to be helped you know a lot of days., Take doing simple things like taking a bath and washing my hair and I just hate to think what's it's going to be like when I get older" (Black-FM).

"I just I don't know what makes me have a lot of energy ... it's hard to explain. Like I said I really don't make plans to do anything because I never know how I'm going to be...I guess it's me. Until I started going to counseling and I guess I was really, I felt this helpless and hopeless and I was real depressed and I cried all the time.” (Black-FM)

\section{Coping and Making Sense of it All}

Participants reported various coping measures to deal with their perceived limitations over the course of their disease. For example, all participants with RA and one participant with FM-RA reported that they pushed their bodies as a way of maintaining control; and that they tried to separate themselves and their self-identities from their conditions. To separate themselves some participants gave names. e.g. 'Arthur' (for Arthritis) for their conditions. Another coping approach was to compare their experiences to conditions perceived to be more severe and life limiting, for e.g. cancer, and to then conclude that, at least, their conditions were not terminal.

In the course of the interviews, participants also revealed various beliefs they held to try to make sense of their disease experiences. One belief was that an individual can accept and live with their condition by focusing on the mind and spirit and not on the body. This belief was mostly evidenced by participants with RA and the two individuals with FM who reported their symptoms somewhat under control. Another belief expressed by some was that when faced with a chronic condition, after doing all that one can do, one must 
surrender and await divine intervention. This belief was mostly evidenced by participants with FM, many of whom reported uncontrolled pain and were frustrated with their medical care. The third belief evident by others was that, whether or not pain was controlled, all things were in the hands of God and under His sovereign control. This view was most commonly expressed by black participants who perceived God as sovereign and reported that pain was an expected part of life. They generally verbalized satisfaction with their current medical care. Irrespective of the belief expressed, all but one participant reported the use of prayers or meditation as a coping strategy. With regards to their disease course, participants with RA generally expected that given the progress of science, there would soon be a cure for RA. However, individuals with FM indicated less positive future expectations. They perceived that they would be disabled early in life and desired to find measures that would enable them to live independently. A sampling of participants' perceptions is listed in Table 7.

Table 7. Exemplars of perceptions related to coping measures.

“...you just have to learn and say to yourself well there are, you know, my God, there are kids in the hospital that have cancer. You know this is like really nothing. This is nothing to what they're going through." (White RA)

"I realize that, you know, changes come whether you have arthritis or not. If you live long enough that change is going to come, because the Bible tells us that. It says if by reason of strength, we live to be 70 years old, and if we live above that then those years will bring misery and things in our lives and see I am experiencing that now. And I accept that because it is the Word of God. And accepting that I can be as happy as can be." (Black-RA)

“Well, it doesn't make you feel very good that you can't do it but by the same token, you have to say well you know at least you are blessed that there is always someone that is in worse condition than you are, so you have to say well you know, this is what I have to deal with." (BlackFM-RA).

"You really have to make a change in attitude. And when I say mind over matter, I really mean it. I mind that my body does this and I'm not going to let it get the better of me... You have to give yourself a mindset that you're not going to succumb to it because it would be very easy to sit down in a chair and never get back up again." (White-FM)

"For me it is because if I gave in to what my body is doing, I wouldn't do anything. And I wouldn't have any pleasure in my life and you get not to do things." (White FM-RA)

"I learned that one thing I could do is separate myself from the pain, you know. I am not the pain. Pain's something that I'm experiencing, something that I have a relationship with, and so therefore we named him “Arthur." (White-RA)

\section{KEY RACIAL DIFFERENCES}

Aside from the disease-specific differences noted, differences in perceptions by race were also evident. First, it was observed that compared to whites, blacks generally focused on the overall outcome of their medical encounterin particular pain relief. Contrastingly, whites focused on the health care-process and often referred to provider communications and lack of follow up care as issues of concern. Similarly, although FMs in both racial groups reported difficulty accessing the health care system for pain relief, once attended to, blacks generally thought that their physicians were doing all they could for them. It should be noted that all but two of the black participants were from the same specialty clinic. As such, this perception may actually be a reflection of the quality of care that blacks received from a common facility and provider. One example of care process concerns raised by Whites FMs was that they felt they were being sent home with a host of medications for pain and other symptoms and that these medications often incapacitated rather than helped them. They verbalized that the global impact of their condition was not generally assessed after their first visit when medications were prescribed and desired more holistic care. Although both black and whites verbalized concerns about medication side effects, more white RAs and FMs stated that they would prefer to deal with the condition than with the side effects of medications that impacted their function. This was not verbalized by most black females who, although concerned about side effects, did not think that avoiding medication was an option. It is again important to note that the majority of the black participants were treated at one local rheumatology clinic and as such this perception may again be a reflection of their common exposure to the same provider. All participants reported that they controlled their conditions by medicating as needed and not always as prescribed. Some white RAs reported that they used medications to structure their day - allowing them to engage in social activities when needed, whereas one black FM reported not taking her FM pain medication on work days because it incapacitated her. She preferred to be in pain rather than incapacitated and unable to work. Compared to white females $(n=5)$ with RA, black females $(n=5)$ were more likely to perceive RA as a natural course of life, an expected condition of aging, or an evidence of a having a longer life span, and were less likely to report feeling distressed by their loss of function over time. They were also more willing to request and participate in support groups.

\section{DISCUSSION}

Profound physical changes and their resultant feelings reportedly influence individuals' self-perceptions and likelihood to proactively seek and manage their care. In this study of a US sample of black and white females with RA and FM, we document common pain experiences between the two conditions but also note group differences in perceptions and interpretations of disease impact. Our findings confirm that of the eight-European country study [22] and the only other study that examined this issue in a multi-racial, sample in the UK [17]. However, our study further documents reported racial differences in diseaserelated perceptions, something the UK study did not do. For example, one difference between black and whites in our study was that older black RAs accepted pain as a normal part of life and exhibited less bother with their symptoms. This finding is contrary to some studies which report that blacks exhibit higher sensitivity to experimental and clinical pain, including arthritis pain [23-25]. Campbell and colleagues note that ethnic differences in experimental pain may be due to hyper-vigilance on the part of blacks [26]. However, Edwards and colleagues suggest that that interpretation of the racial differences in pain reports is difficult because of to the complexity of ascertaining disease severity and medical management of patients' conditions. Rahim-Williams et al. [27] in their systematic review of 
ethnic differences in pain reports conclude that even though there are potentially important ethnic differences in pain perception and reporting, these findings should not just be noted, but should be used to inform care for the various affected patient populations. In our current study, 12 of the 14 black participants were drawn from a musculoskeletal clinic and were under direct treatment by a common rheumatic disease specialist at the time of their interview. It is quite likely that the perception of 'least bother' evidenced by this older segment of black RA participants may have been because of receipt of adequate care at the MSK specialty clinic, which was devoted to their disease condition.

The discounting of disease experiences reported by FMs, in this study, has also been quantified in recent literature [2830]. Using objective measures, Kool and colleagues observed that perceptions of invalidation or discounting were higher for FMs than for RAs and concluded that reasons for this may be due to lack of knowledge about the disease on the part of health care providers, incomplete and ineffective treatment strategies for the condition, and that FM is not high on the priority lists of serious conditions for health care providers [29]. In the previously referenced study of subjects in eight different European countries [22] similar fears, as reported in our study, were documented, suggesting that the perceptions and interpretations of the effect of the chronically, painful rheumatic conditions examined in these studies are not culture-bound.

Finally, the mean BMI in our study indicated an overall obese sample. Although, there has been much written about body image and obesity, little is known about the interaction between obesity-related and inflammatory-disease-related body image perceptions. At the time this qualitative study was conducted, obesity was not featured much in the rheumatic disease literature. In fact, available evidence from population level data dealt mostly with the causal relationship between obesity and isolated rheumatic conditions, for example osteoarthritis [31]. However, in December 2012, a special theme issue of "Obesity and the Rheumatic Diseases" - was published in the journal Arthritis Care \& Research. None of the articles, however exclusively focused on body image perceptions, thus underscoring a continued need for further exploration of body image issues in populations with rheumatic diseases. This study although informative, has several limitations. They first include the low participant numbers which led to the need to supplement the original sample size by recruiting from a local rheumatology clinic. Second, the fact that this was a qualitative study means that the findings are subjective and not quantifiable per se. Third there may have been selection bias in that the inability to reach a large proportion of the original target sample may have been either due to differences in the groups. In fact we were unable to reach many of the participants because of non-functioning phone numbers. It is possible that the unreached group of individuals is demographically different than those who were reached and consented to participate. Lastly this study lacked the clinical records and hence documentation of the disease activity of each patient, and as such could not link disease data to patients' reports. In spite of these limitations however, this study adds valuable insights about the body image perceptions of people with two painful inflammatory and rheumatic conditions and findings could help inform ancillary support therapies for people dealing with these conditions.

\section{CONFLICT OF INTEREST}

The authors confirm that this article content has no conflict of interest.

\section{ACKNOWLEDGEMENTS}

We sincerely thank the staff of the Daughtridge Arthritis Clinic, NC, who assisted with the participant recruitment for this study. This study was funded by a NIAMS Diversity Supplement to grant number R01 AR053989 that provided support for the study and for the primary author. Ms. Schoster and Dr. Callahan were both supported by NIAMS grant \# R01 AR053989.

\section{REFERENCES}

[1] Grogan S. Body image and health: contemporary perspectives. J Health Psychol 2006 11: 523-30.

[2] Thompson JK. Assessing body image disturbance: measures, methodology and implementation. In: Thompson JK, Ed. Body image eating disorders and obesity: an integrative guide for assessment and treatment. Washington DC: American Psychological Association 1996; pp. 49-81.

[3] Lotze M, Moseley GL. Role of distorted body image in pain. Curr Rheumatol Rep 2007; 9: 488-96.

[4] Morrison TG, Kalin R, Morrison MA. Body-image evaluation and body-image investment among adolescents: a test of sociocultural and social comparison theories. Adolescence 2004; 39: 571-92.

[5] Weber C, Bronner E, Thier P, et al. Body experience and mental representation of body image in patients with haematological malignancies and cancer as assessed with the body grid. $\mathrm{Br} \mathrm{J}$ Med Psychol 2001; 74: 507-21.

[6] Thompson JK. Introduction: Body image, eating disorders and obesity- an emerging synthesis. In: Thompson JK, Ed. Body Image, eating disorders and obesity: an integrative guide for assessment and treatment. Washington DC: American Psychological Association 1996; pp. 1-20.

[7] Kraus PL. Body image, decision making, and breast cancer treatment. Cancer Nurs 1999; 22: 421-7.

[8] Anton SD, Perri MG, Riley JR. Discrepancy between actual and ideal body images; Impact on eating and exercise behaviors. Eat Behav 2000; 1: 153-60.

[9] Blouin AG, Goldfield GS. Body-Image and steroid use in male bodybuilders. Int J Eat Disord 1995; 18: 159-65.

[10] McCabe CS, Haigh RC, Shenker NG, Lewis J, Blake DR. Phantoms in rheumatology. Novartis Found Symp 2004; 260: 15474.

[11] Henker FO, 3rd. Body-image conflict following trauma and surgery. Psychosomatics 1979; 20: 812-5.

[12] Macsween A, Brydson G, Fox KR. Physical self-perceptions of women with rheumatoid arthritis. Arthritis Rheum 2004; 51: 95863.

[13] Gutweniger S, Kopp M, Mur E, Gunther V. Body image of women with rheumatoid arthritis. Clin Exp Rheumatol 1999; 17: 413-7.

[14] Centers for Disease Control and Prevention (CDC). Prevalence of doctor-diagnosed arthritis and arthritis-attributable activity limitation - United States, 2010-2012. MMWR Morb Mortal Wkly Rep 2013; 62(44): 869-73.

[15] American College of Rheumatology. Rheumatic diseases in America: The problem, the impact and the answers. Reference: Available from: http://www.rheumatology.org [Accessed on December 23, 2013].

[16] Walker JG, Littlejohn GO. Measuring quality of life in rheumatic conditions. Clin Rheumatol 2007; 26: 671-3.

[17] Harding G, Parsons S, Rahman A, Underwood M. "It struck me that they didn't understand pain": the specialist pain clinic 
experience of patients with chronic musculoskeletal pain. Arthritis Rheum 2005; 53: 691-6.

[18] Monaghan SM, Sharpe L, Denton F, Levy J, Schrieber L, Sensky T. Relationship between appearance and psychological distress in rheumatic diseases. Arthritis Care Res 2007; 57: 303-9.

[19] Taleporos G, McCabe MP. Body image and physical disabilitypersonal perspectives. Soc Sci Med 2002; 54: 971-80.

[20] Gunther V, Locher E, Falkenbach A, et al. Body image in patients with ankylosing spondylitis. Clin Exp Rheumatol 2010; 28: 341-7.

[21] ATLAS/ti. Version 6. [Computer software], Berlin, Scientific Software Development, 2008.

[22] Stamm T, Hieblinger R, Bostrom C, et al. Similar problem in the activities of daily living but different experience: a qualitative analysis in six rheumatic conditions and eight European countries. Musculoskeletal Care 2014; 12: 22-33.

[23] Creamer P, Lethbridge-Cejku M, Hochberg MC. Determinants of pain severity in knee osteoarthritis: effect of demographic and psychosocial variables using 3 pain measures. J Rheumatol 1999; 26: 1785-92.

[24] Edwards RR, Doleys DM, Fillingim RB, Lowery D. Ethnic differences in pain tolerance: clinical implications in a chronic pain population. Psychosom Med 2001; 63: 316-23.

[25] Todd KH. Pain assessment and ethnicity. Ann Emerg Med 1996; 27: $421-3$
$[26]$ 20-6

ailiams B, Riley J, Williams AK, Fillingim RB. A quantitative review of ethnic group differences in experimental pain response: Do biology, psychology, and culture matter? Pain Med 2012; 13: 522-40.

[28] Kool MB, van Middendorp H, Boeije HR, Geenen R Understanding the lack of understanding: invalidation from the perspective of the patient with fibromyalgia. Arthritis Rheum 2009; 61: 1650-6.

[29] Kool MB, van Middendorp H, Lumley MA, et al. Lack of understanding in fibromyalgia and rheumatoid arthritis: The illness Invalidation Inventory (3*I). Ann Rheum Dis 2010; 69: 1990-5.

[30] Kool MB, van de Schoot R, Lopez-Chicheri Garcia I, et al. Measurement invariance of the illness invalidation inventory $(3 * I)$ across language, rheumatic disease and gender. Ann Rheum Dis 2014; 73: 551-6.

[31] Anderson JJ, Felson DT. Factors associated with osteoarthritis of the knee in the first national health and nutrition examination survey (HANES I). Evidence for an association with overweight, race, and physical demands of work. Am J Epidemiol 1988; 128: $179-89$

(C) Boyington et al.; Licensee Bentham Open.

This is an open access article licensed under the terms of the Creative Commons Attribution Non-Commercial License (http://creativecommons.org/licenses/by-nc/ 3.0/) which permits unrestricted, non-commercial use, distribution and reproduction in any medium, provided the work is properly cited. 